\title{
Tempo Presente: entre operações e tramas
}

\section{Present Time: between operations and plots}

\author{
Reinaldo Lindolfo Lohn \\ reilohn@gmail.com \\ Professor Universitário \\ Universidade do Estado de Santa Catarina - Departamento de História \\ Av. Madre Benvenutta, 2007 \\ 88035-001 - Florianópolis - Santa Catarina \\ Brasil \\ Emerson Cesar de Campos \\ ecdcampos@yahoo.com.br \\ Professor Universitário \\ Universidade do Estado de Santa Catarina - Departamento de História \\ Av. Madre Benvenutta, 2007 \\ 88035-001 - Florianópolis - Santa Catarina \\ Brasil
}

\section{Resumo}

O foco deste artigo está em apresentar um quadro das discussões operadas nas últimas três décadas acerca das noções de tempo e de presente em sua junção naquilo que vem sendo chamado de História do Tempo Presente. A elaboração do texto buscou aproximações com a reflexão historiográfica que entende a História do Tempo Presente como o estudo do tempo histórico vivido. As operações e as tramas que envolveram sua constituição acadêmica são o pano de fundo para discutir as redefinições no campo historiográfico acerca das temporalidades e das periodizações. Trata-se de estudo conduzido em função da problemática proposta pela História do Tempo Presente, destacando sua emergência como parte de uma trajetória que não é estranha às experiências sociais aos movimentos historiográficos das últimas décadas.

\section{Palavras-chave}

História do Tempo Presente; Temporalidades; Historiografia.

\begin{abstract}
The focus of this article is to present a framework of discussions over the last three decades on the notions of time and present in their junction in what has been called the History of Present Time. The elaboration of the text sought approximations with the historiographic reflection that understands the History of Present Time as the study of the historical time that is lived. The operations and the plots that involved his academic constitution are the background to discuss redefinitions in the historiographic field over temporalities and periodization. It is a study conducted according to the set of issues proposed by the History of Present Time, highlighting its emergence as part of a journey that is no stranger to social experiences and to last decades' historiographic movements.
\end{abstract}

Keywords

History of the Present Time; Temporalities; Historiography.

Recebido em: 22/12/2016

Aprovado em: 31/8/2017 
[...] vão à mesma companhia velhos e meninos pequenos, uns que, tendo vivido, gastaram todas as suas forças e agora não podem mais

fingir que as têm, outros que, por não saberem governar as que começam a ter, as esgotam em duas horas de carreiras desatinadas, como se o mundo estivesse para acabar e valesse a pena aproveitar os

últimos instantes dele.

(José Saramago).

\section{O tempo presente e suas operações}

Na expressão "História do Tempo Presente" a atenção, tanto de historiadores/ as profissionais quanto do público não especializado, é normalmente direcionada para a palavra "presente". Afinal, dada a forma adquirida pela disciplina ao longo do século XIX, principalmente, quando de sua sistematização como área de saber científico, esta passou a ser apresentada como a "ciência do passado". Tal configuração ganhou ainda mais consistência na medida em que se firmou uma periodização da História a partir de um modelo quadripartite francês que se tornou referência para diferentes historiografias nacionais, a exemplo da brasileira, que mantém ainda, produtiva ou não, estreita ligação com aquela periodização francesa. Ao constituir-se como uma "cartografia" do que seria o tempo histórico universal, o quadripartismo tem óbvias implicações intelectuais e socioculturais ao firmar uma determinada ordem ocidental que se fia no progresso linear e ascendente. Outras tentativas de mapear o que seria a História mundial, como aquelas derivadas do materialismo histórico, não escapariam de um modelo análogo e sucessivo de grandes etapas, saltos evolutivos e teleologias.

Nas narrativas históricas assim tracejadas, como aponta Jean Chesnaux (1995, p. 96-97), em particular a História contemporânea viria encerrar a construção de uma longa linha do tempo e "celebrar a aptidão dos historiadores ocidentais para apresentar um quadro coerente e global do mundo dos séculos XIX e XX, para ser os guias naturais da História africana, asiática ou americana". Diante dessa construção tão coerente quanto frágil em suas pretensões universalizantes, afirmar a possibilidade de uma História do Tempo Presente pode soar estranho ou contraditório, somado à desconfiança quanto à validade de tal empreendimento, objeto ainda considerado muito fugidio e opaco. Entendemos, contudo, que ainda é possível acrescentar elementos a um debate que é certamente um dos que mais mobilizaram contribuições aguçadas e produtivas e que fazem parte da melhor cultura historiográfica desde, pelo menos, o último século.

Consideramos que a possibilidade de elaborar uma História do Tempo Presente traz a oportunidade de refletir sobre outro primado da historiografia, enunciado por Marc Bloch (2001, p. 54-55), o de que a História seria "a ciência dos homens no tempo". Segundo Jacques Le Goff (1994, p. 23-47), com isso Bloch pretendia pontuar três características que considerava essenciais: a produção de uma "história humana", na qual as interações e relações sociais ganham centralidade; daí a necessidade de uma "história social", com intensas relações entre passado e presente; por fim, o trabalho historiográfico deveria recusar sua 
estrita ligação com a cronologia. A partir destas três dimensões, é possível até mesmo estabelecer um diálogo aberto e abrangente com proposições como as de Benedetto Croce, para quem "toda história é história contemporânea", evitando perder-se na ausência de densidade temporal. Para Le Goff, a interação entre passado e presente é a condição para uma história viva e da vida, que se proponha a interrogar o tempo incessantemente, por meio de novas interrogações. Esta seria a própria condição do trabalho histórico em sua relação com a influência cultural das atividades que buscaram uma espécie de domesticação do tempo por meio da invenção de calendários e outros mecanismos de contagem linear, enquanto que os historiadores viriam a preocupar-se por outras dimensões, como a relação entre a história e a memória coletiva.

A relação entre história e tempo tornou-se problemática, envolvendo questões tão abrangentes como a do "sentido da história" e os interesses por diferentes "durações", desde a do tempo muito longo e estrutural até a do passado mais imediato. Nesta dimensão, duas definições fundamentais, aquela referida aos pontos de partida e outra que diz respeito à periodização, com a formação de unidades mensuráveis equivalentes em duração, ganharam contornos menos pronunciados, pois o tempo histórico encontra-se e é atravessado pelo tempo da memória. Constatações que se abrem para compreender que "o historiador está submetido ao tempo em que vive" (LE GOFF 1994, p. 13). Isso significou que a demanda de que passado pudesse explicar o presente por si só tenha se tornado insuficiente para os historiadores, os quais se voltaram para discutir o quanto o presente tem de passado, mas também o quanto este tem de presente. Desde a chamada Escola dos Annales, as diferentes e possíveis concepções de tempo histórico referidas à historiografia acompanham os questionamentos teóricos e metodológicos e as diferentes posições assumidas nos debates acadêmicos e nas abordagens de temas, objetos e processos. Duração, repetibilidade, movimento, estruturas e conjunturas, singularidade e universalidade, diacronia, sincronia e anacronia, memória e imaginação, constituíram-se, por si próprios, em objetos historiográficos, ao passo em que também suscitaram a reflexão quanto a métodos e abordagens adequados à documentação pesquisada e às escalas temporais adotadas. O tempo deixa de ser um pano de fundo para tornar-se a própria trama social construída em distintas dimensões e tensões.

Se a História do Tempo Presente tem sua configuração inexoravelmente ligada à "dimensão temporal" (DELGADO; FERREIRA 2014, p. 7-12), pode-se questionar se o "tempo" referido na expressão que nomeia esta nova abordagem corresponde a um tempo histórico diferente, naquilo que contém em termos de experiências sociais e culturais, ou seja, como dimensão do que se costuma chamar de temporalidade. Do que seria composta esta temporalidade presente? Compreende-se que pode ser demarcada a partir de critérios ainda em construção, naquilo que diz respeito ao vivido tal como se apresenta a cada um ou cada uma, em suas contingências e significados, e que venha a definir episódios e articular o que se passa individual ou coletivamente ao tempo histórico abrangente. Se os últimos movimentos do campo historiográfico voltam-se para o desafio, longe de qualquer zona de conforto, de interrogar os fenômenos sociais do presente com 
vistas a configurar sua temporalidade, então parece ser indispensável questionar elementos característicos deste tempo naquilo que informa as experiências de homens e mulheres, ainda que sob o risco do abandono de "cartografias" do tempo histórico consagradas, em relação às quais a própria História do Tempo Presente permanece tributária. Entendemos que elaborar uma História do Tempo Presente requer, entre outras problemáticas ainda mais complexas, dar-se conta do desafio que subjaz à própria expressão que define esta nova dimensão historiográfica e explorá-la em termos ainda não suficientemente abordados. Pensar o tempo presente e, em particular, este tempo vivido no momento em que se elabora este texto, requer um esforço de reflexão que põe em discussão alguns dos limites de nossa compreensão do "tempo e suas temporalidades", em particular do campo historiográfico como tal.

Portanto, ao empreender este esforço intelectual, é necessário considerar que o próprio tempo histórico em suas implicações para a escrita historiográfica está em questão. Sem pretender simplesmente questionar o quadripartismo, ademais alvo de críticas contundentes há décadas, o que se quer dizer é que uma História do Tempo Presente não deve ser compreendida como mais um pilar na construção do grande e consagrado edifício do tempo histórico, cujo projeto estrutural foi configurado pela historiografia ocidental predominante nos séculos XIX e XX. Uma História do Tempo Presente pode propor-se a discutir este "mapeamento" usual do tempo e evitar aparecer como sua continuidade necessária. Assim, de antemão, o Tempo Presente não seria "mais um período", 100 como se a uma História contemporânea tivesse sequência uma quinta idade, uma quinta era, que necessariamente dará seu lugar a mais um período em um futuro previsível. Pelo contrário, uma História do Tempo Presente compreende uma nova atitude metodológica diante dos problemas enfrentados pela historiografia e pela necessidade de formular reflexões que procurem abarcar sociedade e interações humanas que não mais cabem num mapa histórico desenhado pelo século XIX. Uma História do Tempo Presente pode ser uma contribuição importante para a discussão de fundamentos críticos da área. Por outro lado, como pontua Le Goff (1994, p. 51-53), a história não deixa por isso de ser contemporânea "na medida em que o passado é apreendido no presente e responde, portanto, aos seus interesses, o que não é só inevitável, como legítimo." Se o passado histórico é "passado e presente", este último não deixa de ser também parte da história, ao ser atravessado por experiências de tempo que dizem respeito às formas de registro e de transmissão das informações históricas que se tornaram predominantes desde meados do século $X X$ e que promoveram a emergência do acontecimento e da singularidade.

Acentue-se: não se trata de outra História, tampouco de uma exótica experiência ou aventura em relação ao que seria uma estrutura consolidada. $A$ reflexão sobre uma História do Tempo Presente pode trazer elementos a mais em um processo de discussão e renovação do campo historiográfico que tem como marco evidente a proposta de uma Nova História há cerca de 40 anos. A partir das indicações de Henry Rousso (2012, p. 188-194) em uma de suas mais recentes produções, a denominação História do Tempo Presente surgiu a partir 
do que se pode descrever como uma operação histórica, quando um grupo de historiadores franceses procurou angariar distinção para um campo de interesses específico no interior da historiografia de seu país, ao passo que desejavam legitimidade e cobertura institucional para investigar a História da França da Segunda Guerra Mundial e das décadas da descolonização, em particular a Guerra da Argélia. Ao diferenciar-se da História contemporânea então praticada, logo a organização de um Instituto de História do Tempo Presente demonstraria que uma estratégia acadêmica poderia ser base de uma discussão ampla sobre como apreender processos históricos em movimento e inacabados.

Como aponta Rousso (2012, p. 186), "os historiadores do Tempo Presente, tendo trabalhado sobre questões terrivelmente sensíveis, tiveram de inventar, senão métodos, pelo menos uma maneira de se colocar na paisagem." Uma História engajada em seu tempo, uma História dos vivos e para os vivos, que se recuse a ser a soma de Histórias nacionais e menos ainda um apêndice de grandes cronologias consolidadas, concebendo novas maneiras de fazer e escrever, a partir de interrogações que discutam a própria estruturação do tempo histórico tal como definida desde o Iluminismo. Embora sem admitir a devida referência, os historiadores franceses, a partir de suas próprias necessidades institucionais, buscaram uma denominação que se aproximou daquela existente desde 1949 na Alemanha, no Institut für Zeitgeschichte de Munique (ROUSSO 2012, p. 212-213). O fato do instituto francês não ter resultado de uma grande discussão teórica que levaria à formação de um conceito e daí à sua institucionalização, mas justamente o contrário, não é empecilho, antes é uma vantagem para uma reflexão que diga respeito a não apenas o presente, mas à própria temporalidade tal como se afigura no âmbito da historiografia. Isso quer dizer que a reflexão daí ensejada não se limitou a uma pretensão conjuntural e específica, mas deve dizer respeito às relações mais amplas envolvidas no trabalho do historiador, ao considerar que a distância e o movimento sejam dimensões indispensáveis na relação com objetos, fontes e problemáticas. Por não se tratar de um conceito que se antecipe à investigação, a História do Tempo Presente abre-se à atitudes metodológicas diversas e, ainda que muitas vezes inadvertidamente, possibilita estratégias que põem em causa a necessária discussão sobre o tempo como experiência social e o quanto os fenômenos culturais abarcados pelas investigações historiográficas dependem do reconhecimento das interações entre o que François Hartog (2013, p. 37-41) chama de "regimes de historicidade".

\section{Tramas narrativas}

A partir desse enquadramento, cabe debruçar-se sobre algumas das possibilidades abertas pela proposição, inicialmente como uma operação histórica, de uma História do Tempo Presente que se insinua enquanto possibilidade de pesquisa e reflexão. Considerando o "lugar social" em que a operação foi desencadeada, no Instituto de História do Tempo Presente, na França, e levando em conta a trajetória descrita e analisada por Rousso, na qual não faltam determinações e pressões próprias aos interesses envolvidos 
na institucionalização de um campo de saber historiográfico que se afigurasse distinto e desviante da "História contemporânea", é necessário questionar as implicações sociais desta prática, deste fazer histórico. Isto posto, como pontua Michel de Certeau (2006, p. 80), "quando o historiador supõe que um passado já dado se revela em seu texto, situa-se dessa forma no comportamento dos consumidores. Recebe passivamente os objetos distribuídos pelos produtores". A operação compreende, entre outras práticas, uma "instituição técnica" que age em conformidade com roteiros, modelos e linguagens, os quais atuam como pressões e interditos. Compreendendo a proposta de História do Tempo Presente no interior dessa maquinaria, da qual não escapa o estabelecimento e seleção de fontes, pode-se então acentuar que o tempo a que historiadores e historiadoras do presente remetem suas investigações não será aquele de uma temporalidade fixada a priori, exigindo que a operação técnica possibilite também a observância das fendas nas estruturas científicas predominantes, aquelas que organizam o tempo histórico, e a submetê-las à discussão sobre seus limites. Este último esforço abrange justamente passar do instituído à prática historiográfica, ou seja, no caso, tomar uma História do Tempo Presente tanto como reflexão conceitual quanto como atitude metodológica. Iniciada como operação histórica, a discussão sobre o Tempo Presente passa a envolver então um conjunto de problemáticas que suscita aquilo que talvez seja a mais notória e sólida dificuldade da narrativa sobre o passado: as diferentes percepções de tempo histórico que se cruzam nos objetos estudados, particularmente aquelas

102 que envolvem o próprio pesquisador.

Sabe-se que as narrativas constituem os tramados necessários nos quais são operadas as configurações do tempo histórico, em suas diferentes manifestações e apropriações, situadas entre o vivido e os ritmos da natureza, a ponto de confundi-los. Nesse sentido, pode-se questionar, quanto ao tempo que está presente diante de nós neste início de século XXI, se este demandaria outras formas narrativas e outros delineamentos, distintos daqueles que vêm presidindo a organização do tempo histórico desde a modernidade ocidental. A formulação dessa questão traz implicações não só para objetos próprios ao presente, mas às maneiras de conceber o tempo histórico. Para Paul Ricoeur (2007, p. 456), a História do Tempo Presente é "aquela onde esbarram uma na outra a palavra dos testemunhos ainda viva e a escrita em que já se recolhem os rastros documentários dos acontecimentos considerados".

Esta proposição torna indispensável retomar as proposições de Dominick LaCapra, segundo as quais, considerando as problemáticas relações entre história e memória, pode-se questionar: eventos traumáticos bloqueiam a emergência de memórias e a tentativa de compreensão de processos históricos que afetam, de diferentes maneiras, suas vítimas no presente, com questões morais e representacionais? E os temas sensíveis que dizem respeito às identidades nacionais e aos dilemas que envolvem dívidas históricas? Apenas tardiamente, após certo período de latência, tais assuntos poderiam ser abordados? Estes temas foram extensivamente tratados em sua obra sobre a história e a memória da chamada shoah, palavra hebraica atribuída ao genocídio provocado pela 
Alemanha Nazista contra a população judaica sob seu domínio durante a Segunda Guerra Mundial. Para LaCapra (1998, p. 6-20), não por mera razão cronológica, tanto os eventos ocorridos posteriores à shoah, como também especialmente aqueles que lhe antecederam, não poderiam mais deixar de ser compreendidos e percebidos da mesma forma. Tal evento alterou a apropriação e a experiência do tempo histórico, ao estabelecer um limiar através do qual foi cruzada uma fronteira que deslocou os padrões mínimos de discussão sobre se tal evento pode ser comparável ou sobre sua radical singularidade. Isso quer dizer que algo único ocorreu, dado que os próprios meios de comparação existentes passaram a ser revistos. Pode-se afirmar que tais condições não afetam apenas os relatos testemunhais, mas a própria escrita da história, em especial aquela que se volta para o tempo presente. De tal modo que o binarismo de história e memória ganha outra dimensão, na qual a oposição cede lugar à composição e interação narrativa e ética que possibilita representar um passado doloroso que se faz presente na forma de ensaio e a superação de um insistente "modelo documental restritivo ou objetivista" (LACAPRA 2013, p. 100).

Referências a esta discussão tem sido muito frutífera no Brasil, a partir de diferentes perspectivas, mas cabe destacar o trabalho de reflexão elaborado por Carlos Fico acerca das relações entre história e memória da ditadura militar brasileira. Entre as várias facetas de um trabalho histórico como este, o autor destaca, o constante processo de confrontação entre investigação historiográfica e a memória dos coetâneos, as diferenças entre perspectiva histórica e recuo temporal e as tensões entre a estrita metodologia da história e a memória de eventos traumáticos. Tais problemas constituem um feixe de limites e possibilidades num momento em que a história do tempo presente, como história do vivido, passou a ser necessariamente retomada, dada a demanda por compreender processos históricos que fazem parte da sociedade brasileira pós-ditadura, tais como o aparato repressivo, os conflitos políticos, as vítimas e temas "tabus" como o ingresso de jovens ativistas, oriundos do movimento estudantil, em organizações clandestinas cujos dirigentes mais experientes conheciam os riscos a que os primeiros estavam se submetendo, favorecendo uma "memória traumática" do período da ditadura, tendencialmente reduzida aos episódios da luta armada (FICO 2017, p. 42-51). Contudo, para o autor, a generalização de uma percepção de que a história seria o resultado de constantes, sucessivas e extensivas experiências traumáticas, pode conduzir a determinados exageros, não só retóricos, preferindo identificar fatores como a difusão de uma percepção do tempo marcada pelas mídias e, em particular, a informática e seus desdobramentos na sensação de viver-se em um tempo acelerado que está em pleno desenvolvimento desde, pelo menos, o terço final do século XX (FICO 2012, p. 73-82).

A difusão do rádio, da fotografia, da gravação sonora, do cinema e da televisão, processos vinculados à recente propagação de computadores pessoais e dos meios telemáticos de comunicação viria a somar-se aos meios impressos, tornando-os progressivamente obsoletos e, de certa forma, a desconcertar uma recepção antes dependente do domínio da cultura escrita ou, 
ao menos, da proximidade com círculos de leitores em potencial. No caso das práticas políticas, a necessidade de dirigir-se a multidões diversas e saturada de conflitos sociais e culturais tornou indispensável dar conta de informações as mais abrangentes a respeito do público e de seu comportamento. Os meios de comunicação ascenderam e mantém sua posição central nos jogos políticos. Pierre Nora (1988, p. 181-188) considera que tendem alimentar "uma fome de acontecimentos", o que impõe "imediatamente o vivido como História", ensejando a promoção do "imediato ao histórico".

Não é necessário insistir que tal configuração afeta o ofício historiográfico de diversas formas. Carlo Ginzburg (1991) considera que do descuido para com a reflexão metodológica e aquela voltada a discutir a validade epistemológica de suas premissas e conclusões deriva um movimento ambíguo entre historiadores que em certas ocasiões aderem a atitudes positivistas e cientificistas e, em outros momentos, passam a considerar a História como nada mais do que uma forma literária de expressão. Esta ambiguidade, por vezes, é criativa, mas em outras parece tornar a investigação incapaz de interrogar o que há de experiência vivida nas atitudes e escolhas que envolvem os objetos historiográficos. Em particular, entendemos que há uma inquietação em quase todas as pesquisas que desenvolvem os historiadores: o período. Ao defini-lo de modo "a priori", assumimos também uma série de condições iniciais que tendem, por vezes, a nos gritar: isto não faz parte do meu período. Assim, deliberadamente, é inviabilizada a análise enriquecedora das ocasiões e, em particular, do que há de experiência e temporalidade nos objetos. Essa limitação pode induzir a uma concepção homogênea do social em que parece haver uma única e constante permanência, como se o tempo fosse nada mais do que uma linha que se divide e é cortada em pedaços, ou ainda, o que quase sempre é mais danoso, mal costurada por diferentes meios.

Tal atitude pode muitas vezes ser uma barreira para a compreensão de que em determinado fenômeno social investigado não se está diante apenas de circunstâncias e contextos que explicam e enquadram, mas também diante de "nós" de processos diversos. Esses "nós", na forma como são tramados, dão a entrever indícios de experiências temporais que podem apontar para um vivido próprio de homens e mulheres ali envolvidos. Essas tramas são mais comumente percebidas em momentos que emergem como crises, conflitos, guerras ou mesmo catástrofes. Na forma de tragédias, saltos, recuos e amargores, aquelas mudanças ou transições que a todos impeliriam, ao invés de se mostrarem como esculturas irretocáveis, polidas e acabadas, podem aparecer - numa perspectiva em que se procura o movimento, o inacabado e a indeterminação - como parte integrante da reflexão historiográfica alcançada no entrecruzamento de tempos, ao acelerar experiências e tomadas de posição, ao passo em que contribuem para ampliar as possibilidades de compreensão por parte dos próprios agentes históricos sobre o significado do que se está experimentando. Muito além de mero deslocamento retórico, podem indicar uma crise de paradigmas até então predominantes. Como aponta Emília Viotti da Costa (1998, p. 13-14), "crises são momentos de verdade. Elas trazem à luz os conflitos que na vida diária 
permanecem ocultos sob regras e rotinas do protocolo social, por trás de gestos que as pessoas fazem automaticamente, sem pensar em seus significados e finalidades. Nesses momentos expõe-se as contradições existentes por trás da retórica da hegemonia, consenso e harmonia social".

Tais momentos de verdade dão a entrever o presente de um modo próprio e único, mas carregado de temporalidade. Acostumado à extensão diacrônica dos processos e mesmo de longas durações, o pesquisador é surpreendido com o presente. Uma opção que foi abandonada aos poucos pelos historiadores ao longo do século XX foi a de relegar o presente assim emergido ao que deveria ser uma avaliação posterior, quando houvesse distância dos "fatos". Não é mais possível obedecer confortavelmente às advertências sobre a impossibilidade de pensar o que ainda está a ocorrer, pois é tão necessário questionar quanto de presente há no passado, quanto o oposto. Concebendo o passado e o futuro como poderosas invenções sociais, a historiografia é instada a articular uma análise sincrônica dos fenômenos - mais evidente na aproximação com a Antropologia - à persistente preocupação diacrônica, de modo a dar consistência à própria temporalidade.

Novos enredos interpretativos são necessários para buscar o cruzamento do sincrônico (relativo à simultaneidade ou concomitância) com o diacrônico (referente aos processos ao longo do tempo). Contudo é necessário extrapolar a noção categórica que a matemática impõe. Ou seja, do cruzamento destes eixos o que se obtém é muito mais do que um ponto e um plano. Sim, pois, tomando em consideração o ponto e o plano definidos pelo cruzamento destes eixos como determinantes de ações sociais, teremos no primeiro a continuidade - na qual se encontra a reincidência - e, no segundo, a totalidade que a longa duração pode suscitar - na qual se busca fragmentos. Portanto, ao invés de pensarmos em apenas dois eixos, contemplamos a possibilidade de se considerar uma pluralidade deles, tantos quantos possamos identificar ou sugerir, permitindo análises multidimensionais que constroem sentidos.

Outra possibilidade, entre tantas que se apresentam, é o livre exercício de pesos equilibrados entre a sincronia e a diacronia. Nicole Loraux (1992, p. 57-70) incita os historiadores a uma prática distinta e faz um convite formal ao anacronismo: "o pesadelo do historiador, o pecado capital contra o método, do qual basta apenas o nome para constituir uma acusação infamante, acusação - em suma - de não ser historiador, já que maneja o tempo e os tempos de maneira errônea". Temendo esta possibilidade, o historiador corre o risco de ser impedido de audácia, de analogias e comparações. Em geral, proposições como esta são estigmatizadas como imprudências metodológicas. Há, contudo uma boa carga de perspicácia nesta imprudência, pois permite que outras temporalidades sejam inseridas no tempo dos historiadores. É um tempo que, para a autora, se faz necessário postular, ainda que "fosse apenas para dar um estatuto a tudo aquilo que, em uma época, se pensa adiante dela, no modo da antecipação". Embora invulgar, não é tarefa impossível aquela de identificar trabalhos em que o investigador com rigores metodológicos relativos ao tempo (ou sua periodização) tenha a sensação de estar lidando com realidades e resultados que remetem a outros tempos. 
É preciso, além de compreender o presente pelo passado, interrogar este último com inquietações do presente. Mais: é indispensável compreender a que tempo vivido se está referindo (LOWENTHAL 1998). Por certo, não se conseguirá ressuscitar um passado ao ensaiarmos uma aprendizagem de seu "idioma" (sempre distinto e em mutação). Mas, e quando o objeto de investigação é o próprio tempo do historiador? O que este tem a dizer a respeito de um "país" que não lhe é estranho, pelo contrário, é sua parte viva? Neste caso, parece ser a dimensão do vivido e da própria experiência temporal compartilhada que interessa e não exatamente o ser "presente". Dito de outro modo, e na esteira de Ricoeur (2007), não se trata de se recolher ao trabalho de luto de traumas coletivos de modo a que a sociedade possa seguir em frente. A esta importante e pesada atribuição, a historiografia também pretende abordar o tempo da vida, não só por sua qualidade de estar presente, mas exatamente por ser vivido. De uma narrativa dos mortos, passa-se a uma tentativa de compreender os vivos em seu tempo, em suas experiências. Ao buscar processos em movimento e trajetórias não encerradas, a História do Tempo Presente é uma História da vida e do existir.

Com Hans-Georg Gadamer (1997, p. 436-444) passamos a entender que a interpretação pressupõe uma antecipação de sentido, na medida em que intérprete procura partilhar os significados de um texto com seu autor: "quem quer compreender está vinculado com a coisa em questão que se expressa na transmissão". Há então "uma polaridade entre familiaridade e estranheza" e é nesta intermediação que emergem "as condições sob as quais surge a compreensão". A compreensão dos fenômenos não é limitada, portanto, pela distância temporal, pelo contrário: esta assegura "uma possibilidade positiva e produtiva do compreender" porque permite o surgimento constante de "novas fontes de compreensão que tornam patentes relações de sentido insuspeitadas". Entendido desta forma, o esforço de interpretar compreende um processo inacabado e, em certo sentido, indeterminado. Esta atitude é própria de uma historiografia que pretende compreender a distância e a pertença como partes necessárias de um trabalho de interpretação inacabado e tenso, aberto para a temporalidade e para o acontecimento, tomado, como aponta François Dosse (2001, p. 51), em sua característica de "risco", de "rasgo temporal", como uma "aventura nova". Trata-se de uma postura metodológica que, ao pretender abordar os processos sociais em movimento, conduz ao abandono de formas fixas de descrição do tempo histórico e abre-se para compreender as experiências do passado em suas condições de possibilidade e de imprevisibilidade, privilegiando a ação. É preciso, mais que compreender o presente pelo passado, dotar o passado das características de um presente, em particular a indeterminação, o acaso, as pluralidades e as agências. Eric Hosbsbawm (1995, p. 263), a quem não se deve desconsiderar o quanto sua obra está articulada ao tempo vivido, apontou que uma experiência fundamental dos que viveram grande parte do século $\mathrm{XX}$ foi erroneamente a de alimentar certezas, logo desvanecidas, pois o que aconteceu foi, quase sempre, totalmente inesperado, como no caso do triunfo do capitalismo após "perecer à beira da ruína". 
Desde a Reforma Protestante, para Reinhart Koselleck (2006, p. 21-39), a "temporalização da História" produziu uma "forma peculiar de aceleração que caracteriza a nossa modernidade". O "fim dos tempos" deu lugar a um futuro em que "a aceleração do tempo é tarefa do homem" e é campo de possibilidade probabilidade. Daí surgiu o prognóstico racional e a filosofia da História, esta derivada de uma crença no progresso na forma de "planejamento temporal". A junção dessas duas experiências temporais permanece como vetor cultural indispensável para uma sociedade que se vê fazendo sua própria História. Nessa dimensão, traços, sinais e representações evidenciam a urdidura de "experiências" e "expectativas", entendidas aqui como categorias históricas. Koselleck (2006, p. 305-327) considera que "não há expectativa sem experiência, não há experiência sem expectativa" e o tempo histórico é constituído por tais dimensões, as quais "entrelaçam passado e futuro" e "dirigem as ações concretas no movimento social e político" por meio de relações e configurações assimétricas. Depreende-se que o tempo é uma experiência social que preside trajetórias individuais e coletivas. Krysztof Pomian (1993, p. 104-105) entende que ao longo do século XX, o tempo histórico deixou de ser tomado como um "fluir uniforme" e preestabelecido, o que dotou de importância a observação dos processos sociais, de modo a compreender suas singularidades, variações e ritmos próprios, em períodos curtos ou longos, na forma de modelos que estabelecem uma "sucessão de ciclos, de períodos de desenvolvimento, de declínio, de estagnação, de recomeço". É o caso das cadeias de eventos ordenados e discerníveis que preveem movimentos futuros, próprios dos chamados ciclos econômicos.

Por meio desta tessitura do tempo histórico, conforme Ricoeur (1994, p. 25-26) "narramos as coisas que consideramos verdadeiras e predizemos acontecimentos que ocorrem tal como havíamos antecipado". Esta constatação deixa à historiografia a tarefa justamente de privilegiar e acentuaro indeterminado, bem como tomar eventos, processos e personagens em sua condição de vir-aser e em sua provisoriedade. Nem presente perpétuo e nem eterno retorno, mas uma conjunção de temporalidades por meio de "agenciamento dos fatos", cuja ordenação depende das intencionalidades dos atores que tecem a trama narrativa e reúnem incidentes e fragmentos, por vezes discordantes, numa cadeia de eventos ordenados e discerníveis, com a qual se habilitam a perceberse neste ciclo narrativo e mesmo prever movimentos futuros. Por meio desta tessitura do tempo histórico, "narramos as coisas que consideramos verdadeiras e predizemos acontecimentos que ocorrem tal como havíamos antecipado" (RICOEUR 1994, p. 63).

Assim, para uma historiografia atenta ao Tempo Presente, este não é apenas um simples lugar de passagem, mas uma lacuna e uma possibilidade inacabada entre o passado e o futuro (PEREIRA 2009, p. 230). Isso implica em um trabalho de hermenêutica dos textos pesquisados que pressupõe o diálogo entre o pesquisador e seus testemunhos, a sugerir que os relatos de experiências vividas respondam às indagações do presente, sem que isso signifique esvaziar o passado de sua dimensão singular. As muitas possibilidades das ações humanas 
passam a compor um quadro narrativo que agrega, aos campos de experiência social, os horizontes de expectativa que supõem formações coletivas: "é preciso lutar contra a tendência a se considerar o passado do ponto de vista do acabado, do imutável, do irretocável" (RICOEUR 1997, p. 372). Por outro lado, tal atitude pode favorecer a análise do presente, entendido como parte de um processo histórico aberto e indeterminado.

Obviamente, isto está na dependência de atos interpretativos como parte fundamental da operação historiográfica e que realizam o trabalho "de compreender o todo a partir do individual e o individual a partir do todo" num "movimento circular", como aponta Gadamer (1997, p. 436-444). A interpretação pressupõe uma antecipação de sentido, na medida em que intérprete procura partilhar os significados de um texto com seu autor: "quem quer compreender está vinculado com a coisa em questão que se expressa na transmissão", embora não haja um vínculo contínuo e direto com o texto, como uma "unidade inquestionável". Isso implica em que "existe realmente uma polaridade entre familiaridade e estranheza" e é nesta intermediação que emergem "as condições sob as quais surge a compreensão". No caso de uma interpretação histórica, a compreensão não é limitada pela distância temporal, pelo contrário: esta assegura "uma possibilidade positiva e produtiva do compreender" porque permite o surgimento constante de "novas fontes de compreensão que tornam patentes relações de sentido insuspeitadas".

Fazer entrar em suspensão algumas categorias que levamos para frente 108 ou para trás - passados e futuros, no plural - no vai e vem do pesquisador, não é novidade. É ainda salutar à pesquisa e mesmo indispensável o chamado distanciamento. Contudo, uma condição necessária não significa necessariamente suficiente - quase sempre não o é - e, assim, uma pesquisa não termina, ao contrário, talvez esteja mais próxima do início, de um interessante início, quando arriscamos a não suspender previamente algumas referências que pareçam pertinentes, caminhando no sentido de, conforme Loraux, "ir ao passado com questões do presente, para voltar ao presente com o que se pode compreender do passado". Tal procedimento pode tornar mais visíveis interdições outras, as quais um distanciamento - por estar em demasia vinculado às questões da época - tende a torná-las opacas. Por outro lado, inversamente, não é de toda desordenada. Ou seja, é preciso pensar uma prática controlada do anacronismo, aceitando submeter as referências concebidas como passadas, ou próprias de uma época ou período, às inquietações e indagações que àquela época não foram feitas, ou "pelo menos não formuladas, ou melhor, não recortadas como tais" (LORAUX 1992, p. 61).

Desta forma, a ocasião, reincidência, crise, ou ainda, diacronia, sincronia e anacronismo, nesta oportunidade, se articulam e acabam denunciando a necessidade de pensarmos, ainda uma vez mais, o próprio tempo. Talvez seja produtivo para os historiadores, um contato mais próximo com a física, no sentido de lapidarem suas ideias em relação ao tempo. Evidentemente não se trata de recuperar uma situação desgastada e enfadonha, proposta por uma concepção fortemente influenciada pelo positivismo, tentando aplicar à História, 
a mecânica clássica, que a partir de Newton, impele a uma concepção absoluta do tempo. Trata-se de empreendermos um esforço para buscarmos senão uma compreensão, ao menos um renovado exercício reflexivo sobre o tempo. Laçar uma História, ou Histórias, na dinâmica plural do tempo, é um grande desafio, e pensá-lo numa dimensão de pluralidade e simultaneidade - como fizeram Einstein e Planck, com a teoria da relatividade e todo o escopo da física quântica - é inserir-se nesta perspectiva.

Aprofundando ainda mais tais questionamentos, é indispensável recorrer a Norbert Elias (1998, p. 7) que, ao citar um sábio ancião, sentencia: "quando não me perguntam sobre o tempo, sei o que ele é. Quando me perguntam, não sei". Pensar sobre o tempo em suas dimensões plurais, em seus diversos estratos e camadas que convivem no presente, tendo em vista o que se insinua em tal tarefa, é tanto mais estimulante e fértil quanto forem as perguntas fabricadas por tal empenho. "O que é a experiência do tempo?" (THOMPSON 1998, p. 269). Podemos abordar um tempo sem nos preocuparmos com as diversas maneiras de nos situarmos nele? Que implicações derivam de uma perspectiva reducionista das relações sociais, forjadas a partir de uma única dimensão temporal? Como pensar a natureza do contemporâneo: "tempo fragmentando, tempo deslocado, tempo modelado, tempo representativo-veloz-volátil?" (NOVAES 1992, p. 9). Para mencionar algumas inquietações pertinentes.

Segundo Elias (1998, p. 9), da coexistência entre homens provém algo que eles não entendem, que Ihes parece enigmático e misterioso: o tempo. Entender, por exemplo, que um relógio é um instrumento construído e utilizado pelos homens em função das exigências de sua vida comunitária - e que tenha adquirido uma importância quase absoluta - não é muito difícil, se considerarmos a perfeita distinção entre tempo e relógio, bastante dissimulada a partir da revolução industrial. Contudo, "que o tempo tenha igualmente um caráter instrumental é algo que não se entende com facilidade". Estas concepções, embora distintas quanto à objetividade (Newton) e subjetividade (Kant), entendem o tempo em sua forma natural, ou naturalizadora, e como tal, absoluto.

Por outro lado, podemos pensar a pluralidade de tempos sociais construídos por meio de relações sociais que se cruzam e que também se recusam. A pluralidade evidencia a fragilidade de uma narrativa histórica que se preocupe apenas com o caráter único dos acontecimentos que estuda. O tempo apareceria aí como uma poderosa ferramenta para a formação daquilo que nas Ciências Sociais se chama de configuração social. Há em tais perspectivas a configuração de atores muito bem enredados, mas na qual a "magia social" (BOURDIEU 1996) é simplificada ou até mesmo ignorada. Assim, nessas condições, o tempo é pensado e mostrado como um decalque da realidade, no qual experiências sociais distintas ou práticas e representações sociais são reduzidas a semelhanças estendidas e pretensamente presentes à tonalidade dos atores sociais. Depreende-se disto a atenta desconfiança de uma historiografia renovada com abordagens que impõem divisões e classificações apriorísticas e estruturadas ao social. As formações culturais são múltiplas, como múltiplas (e distintas) são suas concepções de tempo. E, sem dúvida, valores sociais são 
construídos, e destruídos nestes embates temporais: trabalho, lazer, disciplina, projetos políticos, etnicidade, memória, desejos e sonhos.

\section{Temporalidades e indeterminações}

Salvador Dali deixou em uma de suas obras o registro peculiar de um sonho com um queijo camembert derretido. Afirmava não reconhecer a existência senão daquilo que ele conseguisse comer, ouvir, tocar, sentir e ver, ou seja, daquilo que fizesse parte dos sentidos humanos. Daí o seu esforço em compreender o tempo através de uma alusão a relógios que se derretem, como se fossem ser devorados na obra Persistência da Memória, produzida em 1937. Uma referência a um tempo que come e pode ser comido. Podemos pensar, além de um tempo que come - voltado aos eventos da natureza, mesmo que sujeito a ação humana - , e de outros tempos que podem ser digeridos - por práticas e estratégias próprias dos ambientes sociais. Cabe mais uma vez atentar para a observação de Elias (1998, p. 12): "não basta fazer do tempo um objeto tanto da sociologia quanto da física, ou em outras palavras, como muitas vezes se faz, contrastar um tempo 'social' com o tempo 'físico'".

Para Certeau (2006, p. 311), "o tempo que passa, separa ou liga (e que se dúvida jamais foi pensado), não é o tempo programado". Enunciado que se apresenta inicialmente elementar, tem nele uma contundência vantajosa e complexidade de sobra. É lugar comum, em se tratando de tempo, e mesmo se admitindo possibilidades múltiplas, deixar em suspensão um tempo que, por

110 insistir em se comportar fora de uma programação racional, é visto como um acidente, um espaço vazio que a razão cuida de imediatamente ocupar. Uma História do Tempo Presente, como atitude metodológica que se situa no tempo da ação, retira vantagem justamente do acidental, imprevisível e ocasional. Naquelas circunstâncias em que o "acidentado" provoca "falhas no sistema" ou falhas numa estrutura pretensamente acabada, tornando necessário considerar "o ponto cego que (nos) faz ter acesso a uma outra dimensão, a de um pensamento articulado com o diferente como sua inapreensível necessidade".

Uma valiosa contribuição para a abordagem aqui proposta, e que encaminha uma possível síntese das premissas aqui levantadas, é aquela sugerida por Serge Gruzinski (2003, p. 323), ao acentuar a necessidade de histórias múltiplas e conectadas, que não estejam presas a uma única cartografia temporal e especial, "em vez de falar de uma História única e unificada com "h" maiúsculo". Procedendo desta forma, seria possível "a observação de que estas histórias estão ligadas e que se comunicam entre elas". Realidades e temporalidades que se apresentam como elementos constituintes das vivências compartilhadas por diferentes sociedades demandariam ao historiador "converter-se numa espécie de eletricista encarregado de restabelecer as conexões internacionais e intercontinentais que as historiografias nacionais e as histórias culturais desligaram ou esconderam", bem como as grandes narrativas lineares e as classificações abrangentes do tempo histórico. Mais do que a necessária tarefa de pensarmos uma "heterogeneidade multitemporal", compreendida a partir das "contradições e discrepâncias expressadas na heterogeneidade sócio cultural e 
nos conflitos entre diferentes temporalidades históricas que convivem em um mesmo presente" (CANCLINI 1998, p. 83), faz-se mister pensar a pluralidade do tempo de modo relacional, em cruzamentos que se afirmam, se negam e se afastam. Esta proposição nos leva a considerar o tempo como trama de muitas vidas e a experiência do olhar como elemento indispensável, o que importa em considerar não apenas o texto escrito, mas a imagem e o imaginário como possibilidade de apreensão de seus desdobramentos sociais. Neste aspecto da discussão, Georges Didi-Huberman (2015, p. 16) sugere que "o presente pode, de repente, se ver capturado e, ao mesmo tempo, revelado na experiência do olhar", ao surpreender-se com elementos pictóricos abstratos em obras de arte renascentistas, correspondentes a um período histórico bastante documentado e, aparentemente, determinado. Nesta proposição, em uma temporalidade que pode ser apreendida como anacrônica, as imagens podem oferecer outro regime de percepções e aparecer como cruzamentos de tempos e vivências concretas, embora provisórias, por meio de experiências que se operam no tempo presente.

É preciso, portanto, escapar de situações que entendem e afirmam que o "o tempo como sucessão é abstrato e o tempo como simultaneidade é o tempo concreto, já que é o tempo da vida de todos" (SANTOS 1997, p. 160). A distinção vulgar, e estavelmente aceita, que "designa como 'concretos' ou 'reais' apenas os indivíduos de carne e osso e trata como abstrações as formas sociais que se ligam uns aos outros", como aponta Elias (2001, p. 14), contribui decisivamente para um considerável empobrecimento do real. A realidade do tempo histórico pode ser assegurada por uma historiografia atenta às tramas da ação e que não se recuse à imprevisibilidade que é própria dos que vivem no Tempo Presente e percebem que a estabilidade é, por vezes, uma mera impressão, própria de uma forma de narrar o tempo histórico que, apesar de consolidada, deve ser questionada em seu edifício de certezas. Uma História do Tempo Presente que assegure a legitimidade do vivido como parte do tempo histórico, de modo aberto e capaz de suportar as demandas metodológicas de tal empreitada, tão indeterminada e provisória quanto a própria vida. Ao tentar libertar-se das operações que se fizeram necessárias para sua institucionalização, esta nova atitude diante de antigos temas e desafios pode contribuir para a criação de meios para abordar temas difíceis e densos sem deixar de considerar o quanto há de indeterminado e frágil naquilo que constitui as relações sociais, uma historiografia engajada em seu tempo, inquieta e desenvolta, por vezes fugaz, como a vida. Relembrando Saramago, "como se o mundo estivesse para acabar e valesse a pena aproveitar os últimos instantes dele".

\section{Referências bibliográficas}

BLOCH, Marc. Apologia da história ou o ofício de historiador. Rio de Janeiro: Jorge Zahar, 2001.

BOURDIEU, Pierre. A Economia das trocas linguísticas. São Paulo: Edusp, 1996. 
CANCLINI, Nestor Garcia. Culturas híbridas: estratégias para entrar e sair da modernidade. São Paulo: Edusp, 1998.

CERTEAU, Michel de. A Escrita da história. Rio de Janeiro: Forense Universitária, 2006.

CHESNAUX, Jean. Devemos fazer tábua rasa do passado? Sobre a História e os historiadores. São Paulo: Ática, 1995.

COSTA, Emilia Viotti da. Coroas da glória, lágrimas de sangue: rebelião dos escravos de Demerara em 1823. São Paulo: Companhia das Letras, 1998.

DELGADO, Lucília de Almeida Neves; FERREIRA, Marieta de Mores (Org.). História do tempo presente. Rio de Janeiro: Ed. FGV, 2014.

DIDI-HUBERMAN, Georges. Diante do Tempo: História da arte e anacronismo das imagens. Belo Horizonte: Ed. UFMG, 2015.

DOSSE, François. A história à prova do tempo: da história em migalhas ao resgate do sentido. São Paulo: Ed. Unesp, 2001.

ELIAS, Norbert. A sociedade de corte: investigação sobre a sociologia da realeza e da aristocracia de corte. Rio de Janeiro: Jorge Zahar, 2001.

Sobre o tempo. Rio de Janeiro: Jorge Zahar, 1998.

FICO, Carlos. Ditadura militar brasileira: aproximações teóricas e historiográficas. Tempo e Argumento, v. 9, n. 20, p. 5-74, 2017.

História que temos vivido. In: VARELLA, Flávia et al. (Org.). Tempo presente \& usos do passado. Rio de Janeiro: Ed. FGV, 2012, p. 67-100.

GADAMER, Hans-Georg. Verdade e método: traços fundamentais de uma hermenêutica filosófica. Petrópolis: Vozes, 1997.

GINZBURG, Carlo. Apontar e citar. A verdade da história. Revista de História, n. 2, p. 91-106, 1991.

GRUZINSKI, Serge. O historiador, o macaco e a centaura: a "história cultural" no novo milênio. Estudos Avançados, v. 17, n. 49, p. 321-342, 2003.

HARTOG, François. Regimes de historicidade: presentismo e experiências do tempo. Belo Horizonte: Autêntica, 2013.

HOBSBAWM, Eric J. Era dos extremos: o breve século XX (1914-1991). São Paulo: Companhia das Letras, 1995.

KOSELLECK, Reinhart. Futuro passado: contribuição à semântica dos tempos históricos. Rio de Janeiro: Contraponto; Ed. PUC-Rio, 2006.

LACAPRA, Dominick. History and memory after Auschwitz. New York: Cornell University Press, 1998.

. Retórica e história. Territórios e Fronteiras, v. 6, n. 1, p. 97-118, 2013.

LE GOFF, Jacques. História e memória. Campinas: Ed. Unicamp, 1994. 
LORAUX, Nicole. Elogio do anacronismo. In: NOVAES, Adauto (Org.). Tempo e História. São Paulo: Companhia das Letras, 1992, p. 57-70.

LOWENTHAL, David. El pasado es un país extraño. Madri: Akal, 1998.

NORA, Pierre. O retorno do fato. In: LE GOFF, Jacques; NORA, Pierre. História: novos problemas. Rio de Janeiro: Francisco Alves, 1988, p. 179-193.

NOVAES, Adauto (Org.). Tempo e história. São Paulo: Companhia das Letras, 1992.

PEREIRA, Mateus Henrique de Faria. A máquina da memória: o Tempo Presente entre a História e o jornalismo. Bauru: Edusc, 2009.

POMIAN, Kryzstof. Ciclo. In: ROMANO, Ruggiero (Dir.) Enciclopédia Einaudi. Lisboa: Imprensa Nacional, 1993, p. 103-163. v. 29.

RICOEUR, Paul. A memória, a História, o esquecimento. Campinas: Ed. Unicamp, 2007.

. Tempo e narrativa. Campinas: Papirus, 1994. t. I.

Tempo e narrativa. Campinas: Papirus, 1997. t. III.

ROUSSO, Henry. A última catástrofe: a História, o presente, o contemporâneo. Rio de Janeiro: Ed. FGV, 2016.

SANTOS, Milton. A natureza do espaço: técnica e tempo, razão e emoção. São Paulo: HUCITEC, 1997.

SARAMAGO, José. O Evangelho segundo Jesus Cristo. São Paulo: Companhia das Letras, 1991.

THOMPSON, Edward P. Costumes e comum: estudos sobre a cultura popular tradicional. São Paulo: Companhia das Letras, 1998. 